\title{
Comunicación con calidad en Ayahualulco implementando las Tic's para una vida digna
}

Juan Pablo Randell ${ }^{1}$

Margarito Escorcia $^{2}$

\section{Resumen}

La presente investigación se enfoca a analizar la interacción que tienen las personas de Ayahualulco, Veracruz con las tecnologías de la información (TIC'S) y cómo estas han servido para su desarrollo sustentable. Los dos puntos de observación son el educativo y el económico, las tecnologías como nuevas herramientas tratan de llegar a todos los lugares, en las comunidades se capta y se observa una realidad distinta a la que las personas dedicadas a las tecnologías se plantean. Las comunidades con escasos recursos y cuya principal fuente de ingresos es el trabajo de campo, no dependen de las tecnologías y a su aspecto educativo no le prestan más atención que la básica para desarrollarse dentro de su ambiente de carácter rural.

\section{Introducción}

\section{Contexto:}

Las personas de la comunidad de Ayahualulco se encuentran en estado de probreza, la educación es básica y no se puede constatar que los programas educativos cumplan con los estándares debido a que en las comunidades sólo se llega a un cierto nivel de estudios. Las labores cotidianas que ocupan a todas las familias de esta comunidad son el trabajo de campo para sustento propio, el trueque que se da una vez a la semana en la zona urbana de Coscomatepec, trabajos para el hogar y venta de algunos productos básicos como tortilla, tierra, flores y verduras. Las viviendas son rurales, se estructuran de madera, lámina y palmera, los pisos son de tierra y se sigue utilizando el fogón para la elaboración de las comidas.

\section{Planteamiento del Problema:}

Nos planteamos descubrir y analizar cuál es la realidad actual en las comunidades de Ayahualulco en materia de comunicación y cuáles son los recursos con que cuenta para un desarrollo efectivamente sustentable.

\section{Preguntas de Investigación:}

a) ¿Se toman en cuenta su entorno cultural y su circunstancia geográfica para impartirles una educación escolar adecuado con el apoyo de las TIC'S?

b) ¿Qué tanto o de qué forma inciden los Medios de Comunicación Social en la vida y desarrollo de las comunidades de Ayahualulco?

c) La formación escolar que reciben incluyendo el uso de las TIC'S iles permite un desarrollo humano y económico digno?

d) ¿Qué elementos culturales influyen más en su modus vivendi?

e) ¿Qué recursos propios de su entorno se pueden aprovechar para desarrollar un proyecto educativo sustentable?

1 Octavo semestre de la Licenciatura en Ciencias de la Comunicación. (dralocius@hotmail.com)

2 Octavo semestre de la Licenciatura en Ciencias de la Comunicación. (felix_20reyes@hotmail.com) 


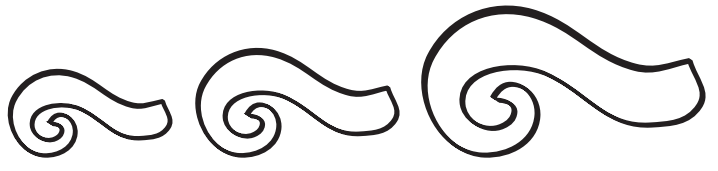

3. Objetivos:

\section{A. Objetivos generales:}

1. Ofrecer a la comunidad un proyecto que coadyuve a una educación desde la promoción humana sustentable aprovechando sus recursos propios o autóctonos e implementando alternativas de mejoramiento haciendo uso de las Tecnologías de la Información que en la actualidad son la herramienta de desarrollo en cualquier nivel social.

2. Conocer la situación que tienen las personas con las TIC's y ayudar a la comunidad de Ayahualulco a tener una mejora en la utilización e implementación de las tecnologías de información para que puedan conocer las innovaciones y mejoras que éstas ofrecen.

\section{B. Objetivos específicos:}

a) Conocer la realidad de Ayahualulco mediante la aplicación de instrumentos válidos para la Investigación Cualitativa que nos permitan diseñar ofertas de mejora para una educación digna y sustentable.

b) Constatar con qué medios de comunicación cuentan y cómo influyen en su diario vivir y desarrollo como comunidad rural.

c) Diseñar y presentar alternativas para un aprovechamiento más crítico y constructivo de los medios para una vida y educación dignas.

\section{Justificación:}

Desde la perspectiva del Documento PERLA, que plantea la Urgencia de una educación desde la promoción del desarrollo humano sostenible, se justifica nuestro trabajo porque

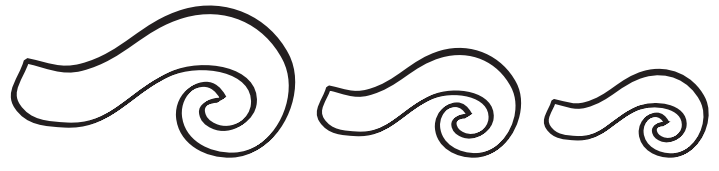

nos acerca a la realidad de las zonas marginales de nuestra patria de una manera directa, objetiva y no sólo como una actividad extramuros que complementa la materia de Investigación Cualitativa, sino también ayudándonos a sensibilizarnos sobre dicha realidad y motivándonos a diseñar y ofrecer a las comunidades investigadas alternativas de mejoramiento.

Desde el punto de vista del Bien Social, la investigación a realizar nos dará oportunidad de integrarnos e interactuar con la comunidad investigada y desde esta experiencia comprenderles y ofrecerles una ayuda real que no se quede sólo en un nivel asistencial, sino que promueva un cambio estructural para su beneficio y progreso humano y educativo.

\section{Marco Teórico}

\section{Marco Histórico}

Ayahualulco es una comunidad rural del estado de Veracruz-Llave, enclavada en la zona montañosa que circunda el volcán Pico de Orizaba. Por su altitud, la mayor parte del año presenta un clima frío, húmedo y con neblinas recurrentes. En su mayoría, la gente se dedica a la agricultura, algunos a la ganadería y otros más a la explotación de los recursos maderables. Las artesanías son otro medio de aportación económica, siendo en su mayoría vendidas en la zona de Coscomatepec.

El nivel socioeconómico es bajo y, en algunos casos, de notable pobreza. Viven en casas rústicas de madera, cartón y pisos de tierra. Aprovechan los productos del campo y de los animales de corral para su alimentación y para el comercio en el que todavía practican el ancestral trueque. El grado escolar predominante es de primaria, debido a sus condiciones y factores económicos, sociales no pueden dar un seguimiento a su desarrollo educativo.

Con la llegada y el trabajo de los Hermanos Lasallistas a la comunidad, se ha mejorado 


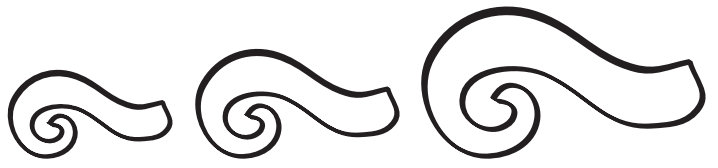

mucho el entorno, pues se han abierto caminos (la carretera pavimentada llega sólo hasta Ayahualulco, los demás son caminos de terracería), se logró introducir el agua potable y la luz eléctrica tanto en Ayahualulco como en las rancherías circunvecinas. Además, han coadyuvado a ir elevando el nivel académico de la población a secundaria y preparatoria. Cuentan también con el apoyo de CONAFE para la capacitación de instructores comunitarios a nivel preprimaria y primaria.

Los partidos políticos con mayor influencia en la región son el PAN y el PRD. Les llega la ayuda económica de los programas "Oportunidades" y "70 y más..." Tienen sus pequeñas clínicas y/o consultorios rurales de la SSA. No hay cobertura de Internet ni de telefonía celular, sino sólo a través de microondas con sistema de antenas repetidoras que, a veces, son saboteadas por manos vandálicas que dejan incomunicada a la población. La TV llega para algunos a través del servicio satelital de VTV.

La cabecera de Ayahualulco cuenta con su Jardín de Niños y Primaria federales, así como la Secundaria y la Preparatoria particulares fundadas por los Hermanos Lasallistas. La Secundaria cuenta además con el servicio de casa-albergue para los jóvenes provenientes de otras comunidades, algunas de ellas bastante lejanas.

La pobreza y bajo nivel académico que aún persiste ha provocado la migración de los jóvenes a las grandes ciudades e incluso a los Estados Unidos en busca de una mejor calidad de vida. También esta situación propicia un alto índice de alcoholismo y violencia intrafamiliar. La mujer es marginada ya que persiste la mentalidad machista en los varones (dentro de este rubro las actividades que realizan ambos sexos son marcadas por la fuerza, habilidades y costumbres).

Aunque un $80 \%$ de la población es de extrac-

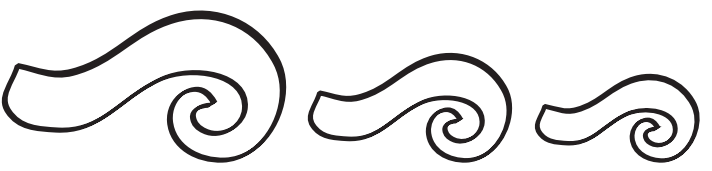

ción u origen indígena náhuatl, se ha perdido, casi por completo, su lengua madre. Conservan algunos de sus usos y costumbres que reflejan un fuerte sincretismo religioso, aunque la atención religiosa por parte de la Iglesia Católica es bastante limitada por la escasez de sacerdotes y lo numeroso y disperso de las comunidades.

En cuanto a las tecnologías de la información se refiere, la comunidad desconoce los usos y beneficios que pueden aportar al crecimiento de la sociedad en general. Los jóvenes son lo que tienen un contacto significativo, sin embargo, el uso que le dan a esta herramienta es mala, perjudicial y superficial. El tiempo es otro factor de limitación para el uso y desarrollo de las tecnologías de la información; la Universidad La Salle por medio de sus programas de desarrollo (Proyecto Perla, 2005) ha planteado un seguimiento para que la comunidad de Ayahualulco pueda generar proyectos y un desarrollo sustentable por medio de las TIC'S.

En general la población de esta comunidad es amable y hospitalaria, sobre todo con los visitantes avalados por la Universidad La Salle, pues reconocen y saben agradecer toda la obra de mejoramiento social y acompañamiento que han llevado a cabo los Hermanos Lasallistas en sus comunidades durante muchos años. Algunos rechazan la oportunidad de crecer debido al miedo del crecimiento urbano y las represalias políticas (perder el apoyo alimenticio o de vivienda), por lo que simplemente viven al día.

Con el paso del tiempo se nota un conocimiento mayor sobre las tecnologías de la información, la aplicación adecuada para los que tienen acceso a los cursos que ofrece la universidad. En un periodo a largo plazo se podría llegar a la comunidad en general.

Finalmente la incorporación de tecnologías de la información y las comunicaciones no es la simple mediación a través de ellas. Hay que 


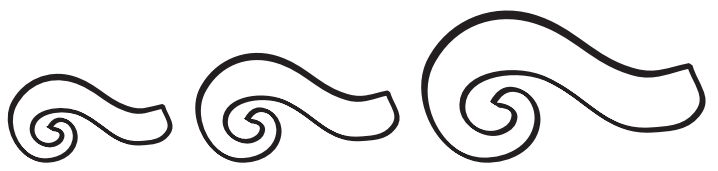

superar la interpretación "artefactual" del uso de las tecnologías en la educación. La simple instalación y uso de elementos electrónicos en una sala de clases no da mecánicamente aprendizajes en entornos virtuales. Se trata de trabajar el aprendizaje con alumnos protagonistas de su propio aprendizaje a través de sus competencias tecnológicas-culturales concretas y específicas. Se trata de desarrollar una tecnología educativa crítica con un enfoque holístico, es decir, que entienda la diversidad de factores que da origen a múltiples dimensiones de cada proceso que vive el alumno, que propenda a la formación de alumnos interactivos, con comprensión inteligente de lo que observan, que vayan construyendo su realidad a partir de poderosos conocimientos previos siempre fortalecidos con enfoques integrales de la realidad, e incorporando crítica, reflexiva, apropiada y de manera contextuallas TICs.

\section{Marco Teórico}

Dimensiones de las teorías de la comunicación educativa (Mg. Zulma Aramayo UCASAL (1996):

1) Teórica - tecnológica: investiga las vías más eficaces para transmitir la información y el conocimiento en la educación formal y no formal.

2) Relación docente alumno en procesos de enseñanza y aprendizaje.

La comunicación pedagógica: fruto de la psicología social y de la pedagogía marxista soviética, que enriquecidas en el contexto de la Cuba socialista, sirve de base para la conformación de un cuerpo teórico integrador, capaz de fundamentar las regularidades y principios que rigen la actividad comunicativa en los procesos escolarizados.

A criterio de la Dra. Ana María Fernández (1997) el objeto de estudio de la comunicación

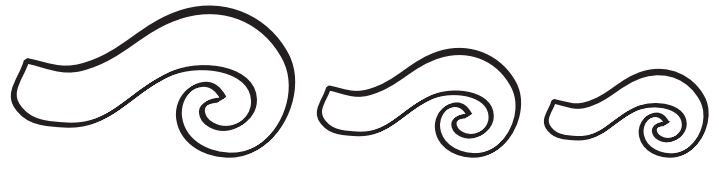

educativa, es el estudio de los principios que rigen las interacciones comunicativas que se desarrollan durante el proceso educativo en todas sus dimensiones.

La autora se refiere en este caso, a las interacciones de alta significación para los interlocutores que participan en el proceso comunicativo educativo, que lleva implícito propiciar un cambio de actitud definitiva o temporal de los sujetos participantes.

La actividad comunicativa - educativa no sólo transmite contenidos, sino que también forma convicciones, sentimientos y desarrolla la personalidad, por ello nos inclinamos a expresarlo como proceso comunicativo - educativo, relación que expresa todos los elementos que la integran haciendo énfasis tanto en la elaboración y transmisión del mensaje de acuerdo a la interacción emisor - receptor, así como en sus resultados.

La comunicación educativa como el resto de los procesos sociales, se encuentra determinada por las relaciones sociales y las normas culturales que rigen en el contexto en el cual se producen, por consiguiente, se desarrollan en la medida en que lo hace la sociedad. De ahí que los procesos comunicativos consideren el contexto educacional social, general y particular, las condiciones reales de existencia en que se producen y en especial las características culturales de los interlocutores (http://www.slideshare.net/zulmaaramayo/co municación-educativa-presentación, 2012).

\section{Marco Conceptual}

\section{Comunicación:}

La comunicación es el proceso mediante el cual el emisor y el receptor establecen una conexión en un momento y espacio determinados para transmitir, intercambiar o compartir ideas, información o significados que son comprensibles para ambos. 


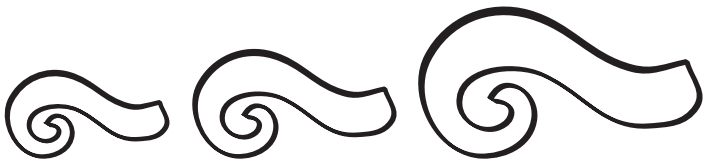

Desglosando esta respuesta (para una mejor comprensión), diremos que la comunicación es un proceso que (en general) incluye los siguientes pasos:

a) el deseo de un emisor de transmitir un mensaje a un receptor,

b) la codificación de ese mensaje para que sea comprensible,

c) el envío del mensaje mediante un canal,

d) la recepción y decodificación del mensaje por parte del receptor, $y$

e) la respuesta o retroalimentación del receptor al emisor.

Está conformada por un emisor y un receptor que están predispuestos a enviar y/o recibir un mensaje entre ellos.

Es un medio que establece una conexión entre el emisor y el receptor en un momento dado y en un espacio físico o virtual determinado.

Es utilizada para transmitir, intercambiar o compartir mensajes. Por tanto, puede ser un proceso dinámico de ida y vuelta entre el emisor y el receptor o solamente una transmisión del emisor al receptor.

Hace que las ideas, información o significados que son comprensibles tanto para el emisor como para el receptor fluya entre ambos. (http://www.slideshare.net/pablosolerarte/en -el-campo-de-la-comunicacion? from_search $=9$ ).

\section{Educación:}

Desarrollar o perfeccionar las facultades intelectuales y morales del niño o del joven por medio de preceptos, ejercicios, ejemplos, etc. Educar la inteligencia, la voluntad.

Es importante destacar que en México es un derecho fundamental de los individuos, consagrado en nuestra misma Constitución que aspira a una Educación de Calidad:

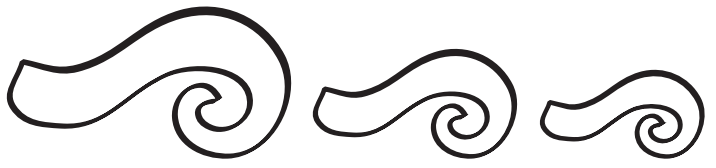

Art. 3o La educación que imparte el Estado tenderá a desarrollar armónicamente todas las facultades del ser humano y fomentará en él, a la vez, el amor a la Patria y la conciencia de la solidaridad internacional en la independencia y en la justicia.

Será democrática, considerando a la democracia como un sistema de vida fundado en el constante mejoramiento económico, social y cultural del pueblo. Atenderá a la comprensión de nuestros problemas, al aprovechamiento de nuestros recursos y acrecentamiento de nuestra cultura.

Contribuirá a la mejor convivencia humana, tanto, por los elementos que aporte a fin de robustecer en el educando, junto con el aprecio para la dignidad de la persona y la integridad de la familia, la convicción del interés general de la sociedad, cuanto por el cuidado que ponga en sustentar los ideales de fraternidad e igualdad de derechos de todos los hombres, evitando los privilegios de razas, de religión, de grupos, de sexo o de individuos (http://www.slideshare.net/estefaniafernande z12720100/presentacion-derecho-a-laeducacion?from_search $=7$ ).

\section{Desarrollo sustentable:}

Se llama desarrollo sustentable o sostenible a aquel desarrollo que es capaz de satisfacer las necesidades actuales sin comprometer los recursos y posibilidades de las futuras generaciones. Intuitivamente una actividad sostenible es aquélla que se puede mantener. Por ejemplo, cortar árboles de un bosque asegurando la repoblación es una actividad sostenible. Por el contrario, consumir petróleo no es sostenible con los conocimientos actuales, ya que no se conoce ningún sistema para crear petróleo a partir de la biomasa. Hoy sabemos que una buena parte de las actividades humanas no son sostenibles a medio y largo plazo tal y como hoy están planteadas. 


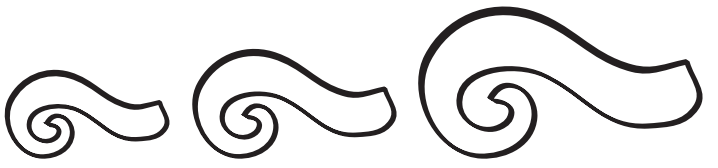

Esta definición es la del informe de la Comisión Brundlandt. La señora Brundlandt es la primera ministra de Noruega y el año 1990 recibió el encargo de la ONU de redactar un primer informe para preparar la Cumbre de la Tierra de Río de Janeiro dos años más tarde.

Otra definición se debe a H. Daly. Esta persona propone que una sociedad sostenible es aquélla en la que:

- Los recursos no se deben utilizar a un ritmo superior al de su ritmo de regeneración,

- No se emiten contaminantes a un ritmo superior al que el sistema natural es capaz de absorber o neutralizar,

- Los recursos no renovables se deben utilizar a un ritmo más bajo que el que el capital humano creado pueda reemplazar al capital natural perdido.

Concretando esta definición en un caso práctico, el de los combustibles fósiles, significa que se tiene que utilizar una parte de la energía liberada para crear sistemas de ahorro de energía o sistemas para hacer posible el uso de energías renovables que proporcionen la misma cantidad de energía que el combustible fósil consumido.

\section{Vida digna:}

Vida digna es la condición natural, inherente al ser humano, la cual le proporciona un posición en la sociedad de inclusión, merecidamente con justicia y razón; invistiéndola de dignidad como un derecho natural de aquél, que impulsa al ciudadano a una calidad personal, familiar, social y económica aceptable. $\mathrm{O}$ también entendemos como Vida digna aquella en la cual una persona valora y/o es valorada en sus derechos, así como sus deberes para con la sociedad. Respeta, solidariza, es generosa, ecuánime, justa y honesta.

Respeta los límites de su libertad con respecto

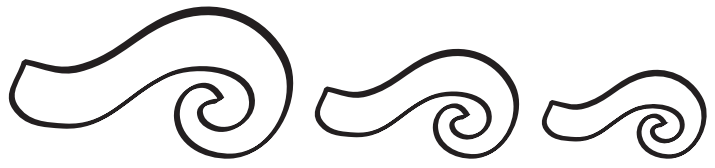

a otros. Pero por encima de eso, desarrolla todas sus habilidades y aptitudes, para no ser un parásito para los demás sino por el contrario le aporta y le suma a su vida y a la sociedad.

La vida digna la desarrolla el modelamiento social que facilita la cultura, ésta ofrece elementos motivantes que permiten una causaefecto en las vidas de los pueblos. En este caso el efecto, se logra observar en el nivel de participación social del ciudadano, en su inclusión real en la sociedad. (http://www.eui.upm.es/ $\sim$ rafami/TICyDH/material05/ Tema1/ Alumnos-VidaDigna-DesarrolloHumano.pdf).

\section{Tecnologías de la Información (TIC'S)}

Agrupan los elementos y las técnicas usados en el tratamiento y la transmisión de la información, principalmente la informática, Internet y las telecomunicaciones. Las tecnologías de la información y la comunicación pueden mejorar la vida de todos los habitantes del planeta, ya que se dispone de herramientas para llegar a los objetivos de desarrollo de la edad moderna, de instrumentos que harán avanzar la causa de la libertad y la democracia y de los medios necesarios para propagar los conocimientos y facilitar la comprensión mutua.

\section{Marco Referencial}

Apoyándonos de las investigaciones de otros autores, podemos darnos cuenta de cómo el nivel educativo en algunas comunidades es deprimente. Por ello es necesaria la investigación para saber porque se está fallando en este aspecto, dando así algunas posibles soluciones para terminar con este nivel educativo tan bajo que se vive en casi todo el país.

Los primeros modelos que aparecen en el estudio de la calidad educativa, surgidos en toda la problemática de la eficacia de la escuela, son los modelos de Entra-Producto, en los que la 


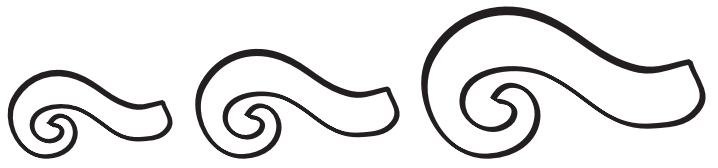

escuela se considera como un sistema de atributos en la que hay que analizar la relación existente entre los diferentes productos y sus respectivas entradas, recurriendo a un planteamiento aditivo cuando se quiere explicar la importancia de los diferentes factores considerados (Muñoz Repiso, 1996). El objetivo último de estos modelos es identificar las variables de entrada que producen alteraciones en el producto (Fuentes, 1986), entendiendo lo que sucede en la escuela durante el proceso de enseñanza- aprendizaje.

Es importante saber sobre otras investigaciones realizadas, para una mejor visión de lo que se quiere lograr, como se mencionó anteriormente, hay que saber qué factores son los que ocasionan que no exista en las escuelas una educación con calidad.

Para la elaboración de este modelo, sus autores parten de la integración de múltiples perspectivas de la calidad de la educación (eficacia, aceptabilidad, eficiencia, acceso, equidad y relevancia) para evaluar la misma en la etapa de educación infantil, adaptando cada una de estas perspectivas a esta etapa concreta, y dando lugar a un modelo estructurado en aspectos de entrada, de proceso y de producto.

En términos generales, la eficacia se refiere a la capacidad de cumplir las funciones destinadas a la etapa, de lograr los resultados esperados en todos los ámbitos de desarrollo y de conseguir la satisfacción de los directa e indirectamente implicados en el proceso; la aceptabilidad, a la naturaleza de las relaciones mantenidas entre los implicados y a la creación de un clima adecuado para los niños; la eficiencia, hace referencia al coste del servicio, tanto a nivel económico como personal, la optimización de procesos y resultados educativos en función de los recursos asignados.

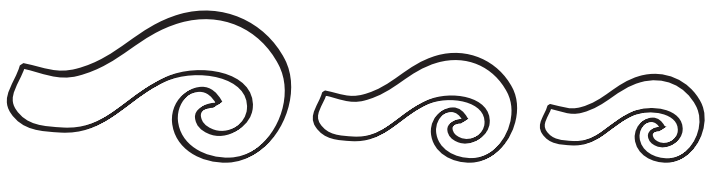

Metodología

\section{a) Enfoque: Cualitativo}

El enfoque de la presente investigación es cualitativo ya que se analizará el sistema educativo y su relación con las TIC'S para un desarrollo sustentable, la observación de la naturaleza y la situación actual de las personas de Ayahualulco será parte de esta investigación. Con el análisis basado en la observación y otros instrumentos de medición cualitativa se estudiará la situación actual, la función de las TIC'S, el uso que la comunidad les da y cómo forma parte del desarrollo de su educación.

\section{b) Alcance: Descriptivo}

En esta investigación se propondrá en describir la situación de la educación y su relación con las TIC'S, cómo es y cómo se manifiesta en la comunidad de Ayahualulco. El estudio descriptivo nos permite especificar las propiedades, las características y los perfiles importantes del tema escogido, la educación y las TIC'S, sometiéndolo también a un análisis. Se medirán, evaluarán y recolectarán datos sobre diversos aspectos, como el uso de las TIC'S, el tiempo que se le dedica, y cómo se utilizan en su beneficio. Después de la recolección de información de cada elemento o indicador se analizarán y consecuentemente se describirá la situación actual y cada una de sus características así como las nuevas que se llegaran a descubrir.

\section{c) Diseño: No Experimental}

El diseño es no experimental ya que no se realizarán experimentos con los sujetos de estudio sino que únicamente se estudiará, analizará y observará la situación relacionada con nuestro tema y sus variables por lo que parte del diseño no experimental incluye uno de los puntos de su clasificación que es el transversal. Es transversal porque se recopilarán datos en un solo momento, en un tiempo único, en este 


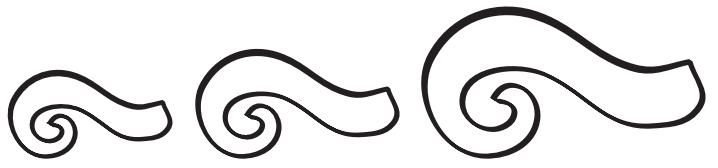

caso una semana. El propósito es describir variables y analizar su incidencia e interrelación a lo largo de su vida cotidiana.

\section{d) Contexto:}

El contexto de la investigación se ubica, geográficamente, en el estado mexicano de Veracruz en las estribaciones serranas del volcán Pico de Orizaba y en el municipio de Ayahualulco. Las comunidades que conforman este municipio son fundamentalmente campesinas y de extracción indígena u origen totonaco. La principal lengua indígena es el náhuatl, aunque la mayor parte de la población actualmente habla el español.

El contexto educativo nos habla de la existencia de educación básica impartida en 20 planteles de preescolar, 26 de primaria, 4 de secundaria. Además cuenta con una institución que brinda el bachillerato. Y en lo que se refiere a Medios de Comunicación, en el municipio se captan las señales de televisión vía satélite y 10 señales de radio en AM y 10 en FM. Tienen servicio telefónico por marcación automática en la cabecera y 9 localidades, así como con telefonía rural y 4 oficinas postales.

Por otra parte, el trabajo se enmarca dentro de la labor pastoral, y sobre todo académica, que los hermanos lasallistas han realizado allí desde hace varios años, además de los trabajos que han realizado compañeros de generaciones anteriores de la misma carrera o de otras.

\section{e) Población/Muestra/Sujeto:}

Realizaremos el trabajo de investigación entre población de las comunidades del municipio que son de carácter rural y que han ido poco a poco saliendo de un cuadro de notable marginación. Tomaremos, como muestra no probabilística, tanto a los maestros de las escuelas, como a sus alumnos. Y como informantes

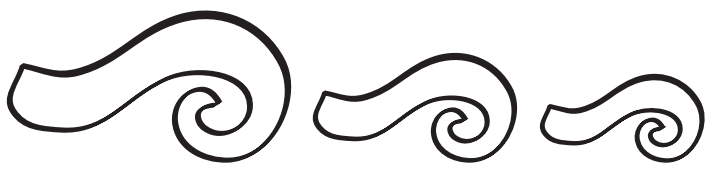

cualificados, especialmente a los directores (as) de los planteles. No pretendemos sólo hacer un trabajo cuantitativo recabando cantidades, sino cualitativo con base en las respuestas que nos den y nos permitirán tener no sólo un conocimiento más certero de su realidad, sino hacer un diagnóstico apropiado y diseñar propuestas de mejora para la misma comunidad.

\section{f) Supuesto:}

Constatar el grado de conocimiento y uso de las TIC's entre la población escolar así como su aplicación en su vida cotidiana, es decir, cuáles usan, cómo las usan y sobre todo, cómo influyen en su vida y desarrollo comunitario; si coadyuvan a una vida digna y desarrollo integral en o para la comunidad.

\section{g) Procedimiento:}

Realizaremos el trabajo en equipo, de manera organizada y respetando los folios de cada instrumento, empezando por aplicar la entrevista a niños, jóvenes y adultos en escuelas de diferentes comunidades de Ayahualulco, así como en diferentes hogares de la región, de acuerdo a la guía o cuestionario que hemos elaborado.

Será relevante la entrevista a los informantes cualificados. Durante la aplicación de la misma, se buscará recabar la mayor información e incluso lograr obtener datos más allá del propio cuestionario.

A la entrevista le complementará la Observación estructurada y directa, la personal y grupal que luego conjuntaremos, con la finalidad de obtener resultados, reales, duros y confiables, además de obtener datos más profundos y contextualizados a la zona en que serán aplicados dichos instrumentos, mismos que anexaremos en la investigación. 


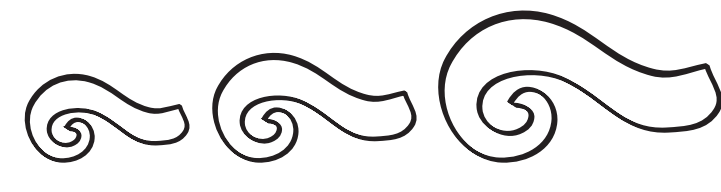

Edad:

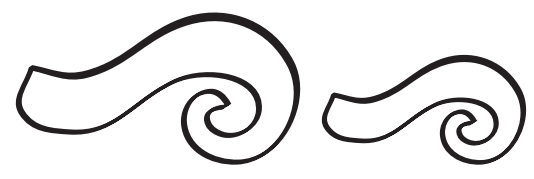

Folio:

Nivel de Estudios:

\section{Educación con calidad en Ayahualulco implementando las TIC'S para una vida digna.}

Objetivo: Conocer la situación que tienen las personas con las TIC'S y ayudar a la comunidad de Ayahualulco a tener una mejora en la utilización e implementación de la tecnologías de información y que puedan conocer las innovaciones y mejoras que ofrecen estas.

Bloque I: Lo conocido

1. ¿Hace cuánto que hace uso de la tecnología?

2. ¿Cómo era su formación educativa antes de que conociera las TIC'S?

3. ¿Qué usos prácticos le ha dado a esas tecnologías?

4. En cuestión educativa, ¿cómo han influido las tecnologías en su vida?

Bloque II: Actualidad

5. ¿Qué importancia tiene su formación educativa?

6. ¿Qué herramientas conoce de las TIC'S que le han beneficiado educativamente?

7. ¿Le es complicado el uso de las tecnologías a las que tiene acceso?

8. ¿Cuánto tiempo le dedica al manejo de las TIC'S y en qué lo utiliza?

\section{Observaciones:}

Entrevistador (a): . Fecha: 


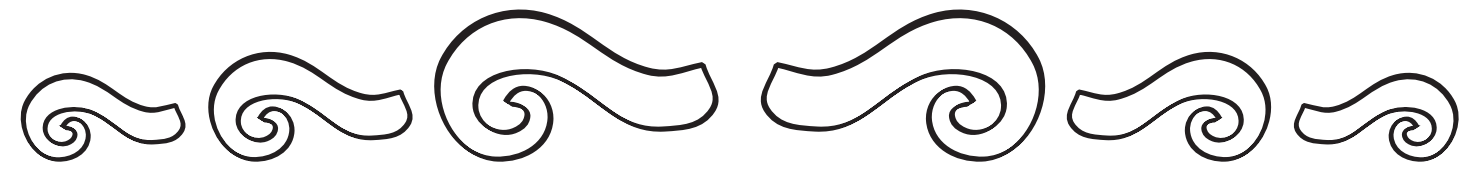

HISTORIA DE VIDA

Nombre:

Edad:

Sexo:

Ocupación:

Indicaciones:

a) Narra el momento en que llegaste a la Casa Hogar, tu testimonio es valioso para la elaboración de instrumentos que nos permitan observar los cambios que ocurren en los niños que pasan por algo similar.

b) Es importante que incluyas: ¿Cuándo sucedió? ¿Por qué sucedió? ¿Qué cambios hubo en tu persona? (físicos, psicológicos, económicos, sociales) ¿Estás feliz por lo que has logrado? (No contestes las preguntas únicamente. Debe ser narración).

c) Tu información es confidencial y exclusivamente el investigador tendrá acceso a ella.

d) Puedes ocupar ambos lados de la hoja.

e) iGracias por tu participación!

\section{Análisis de datos}

El trabajo de investigación fue realizado en la región de Ayahualulco, Ver., del 20 al 25 de mayo de 2012. Es una región rural de origen indígena totonaca enclavada en la zona montañosa de las faldas del volcán Pico de Orizaba. Se trata de un área de alta pobreza que ha ido poco a poco logrando su progreso con la presencia y el trabajo de los Hermanos Lasallistas que crearon una casa albergue, una telesecundaria y un bachillerato, además de promover obras sociales como electrificación, agua potable, carreteras, etc. La institución lasallistas constituye un caso atípico que con- trasta fuertemente con las circunstancias sociales y culturales del lugar como son: pobreza, alcoholismo, violencia intrafamiliar, escasas fuentes de empleo, etc.

En cuestión educativa, constatamos que el nivel de primaria es el más alto, de los 50 entrevistados, 31 contestaron estar en este nivel. Las rancherías cuentan al menos con una pequeña escuelita primaria. En Ayahualulco se cuenta además con la Telesecundaria y el Bachillerato Tecnológico fundados por los Hermanos Lasallistas. 


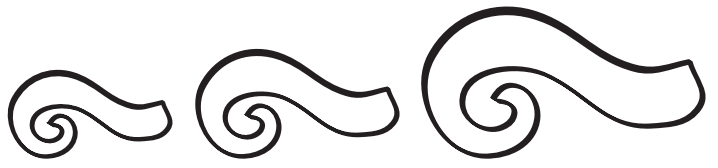

Por lo que toca a las comunicaciones, es una región donde no llegan las señales abiertas de TV, telefonía celular ni Internet. Sólo vía satelital y/o de microondas: la Telesecundaria y Bachillerato cuentan con sus respectivas antenas y sistema propio para recibir las señales. Únicamente en Ayahualulco hay servicio de telefonía fija y caseta pública. Las familias con mayores posibilidades económicas cuentan con servicio de Sky o VTV para sus televisores. Los radios sí captan unas cuantas estaciones.

Se aplicaron dos instrumentos de Investigación Cualitativa: Entrevista directa y Observación. Se aplicaron 50 entrevistas y sólo 10 instrumentos de observación. Comenzamos la aplicación en la Escuela Primaria Estatal Nicolás Bravo, turno matutino, de Coscomatepec, Ver. Posteriormente, se aplicaron también en Ayahualulco y las rancherías aledañas a este pueblo: Rancho Nuevo, Rancho Alegre, La Mesa de Buenavista, La Manzanita y Unión Chirinos.

La mayor parte de las personas entrevistadas fueron adolescentes y jóvenes, pero también adultos, en promedio de $50 \%$ y $50 \%$. En Coscomatepec aplicamos 16 instrumentos de Entrevista, los otros 34 en Ayahualulco y sus alrededores. Este trabajo de campo se realizó de lunes a jueves por las mañanas en horario de 8 a 11:00 a.m. Los Instrumentos de Observación fue difícil aplicarlos, sólo se concretaron 10 en escuelas y casas particulares de Ayahualulco y sus rancherías.

Fueron entrevistados 27 mujeres y 23 hombres. El mayor nivel académico es de primaria con 31 personas, sólo una con carrera terminada y 6 que no estudiaron nada o no terminaron ni siquiera la primaria. De las herramientas que más conocen y/o manejan, tenemos que lo más común es la televisión (27 personas), luego Internet (23 personas) y telefonía celular (11 personas). Muchos no usan el telé-

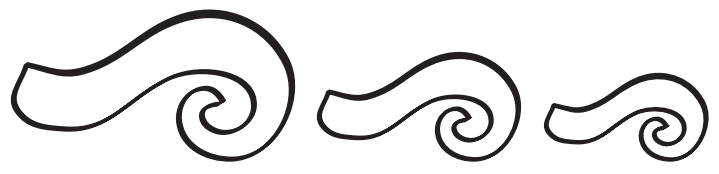

fono celular por el problema de que no hay cobertura en la región; otros lo usan sólo para jugar y/o escuchar música.

En general, la mayoría tiene poco tiempo de conocer y manejar las TIC's, 13 personas contestaron que sólo de hace 3 años para acá, 8 desde hace 2 y otras 8 desde hace 5 . En cuanto al tiempo diario de uso, 13 personas dedican 1 hora diaria (especialmente a la TV), 12 personas admitieron que 2 horas al día.

La mayoría (18 personas) contestó que su formación anterior al conocimiento de las TIC's era al modo tradicional con los instrumentos de libros, enseñanza del maestro y uso del pizarrón con gises (12 personas). Además era más complicada y difícil ( 9 personas). Sobre el uso práctico de las TIC's, 28 las usan para entretenimiento, 15 para buscar información diversa y 11 para comunicación. En cuanto a la influencia educativa, 9 no las usan, a 10 les facilita su estudio o tareas, 8 las ocupan para actualizarse y a 8 les sirven de apoyo en su trabajo. 26 personas le conceden mucha importancia a las TIC's en su formación, 11 muy poca, a 9 les ha servido para mejorar y 3 no le dan ninguna importancia o no les encuentran utilidad. Para 26 no es complicado su uso, para 17 sí y para 6 a veces.

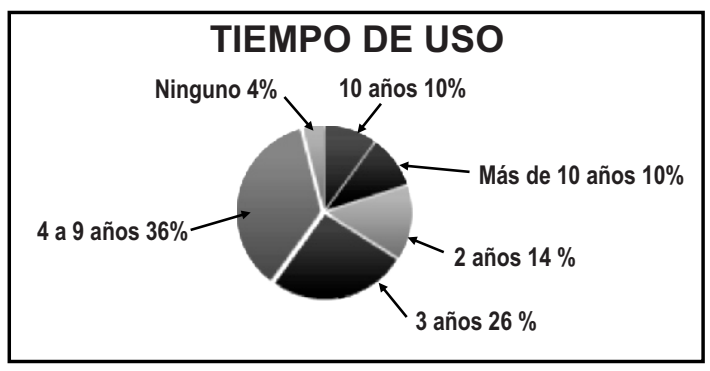

El tiempo de uso que las personas le han dedicado a las tecnologías desde que las conocieron varia en 6 rangos, en relación de 3 a 9 años conjugan un valor de $62 \%$ por lo que dentro de ese valor se sabe que los habitantes tienen mayor contacto y obtienen un dominio aceptable de estas tecnologías. 

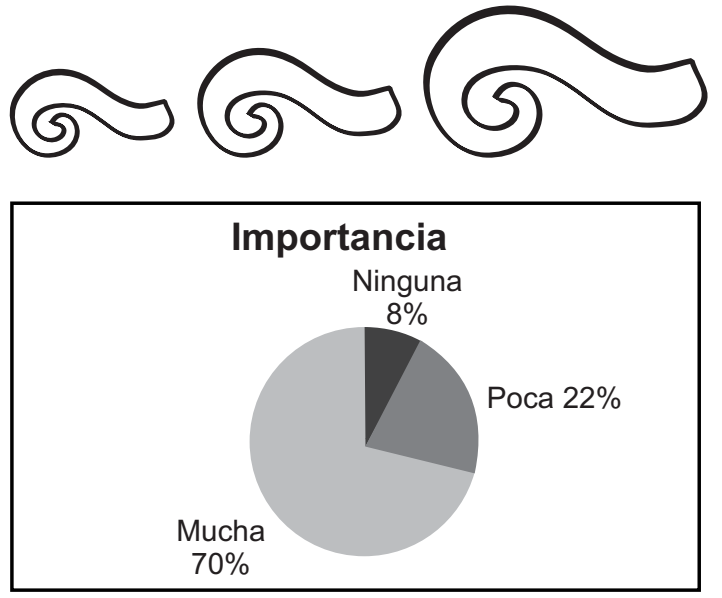

La importancia para los habitantes que consideran las tecnologías de la información es mucha debido a que lo piensan como una forma más de incrementar su ingreso general, los negativos contestaron debido a que su nula participación e interacción no les permite conocer los que las tecnologías les ofrecen, aunque en un panorama general todavía ninguno de los habitante se atreve a emprender un proyecto con las tecnologías.

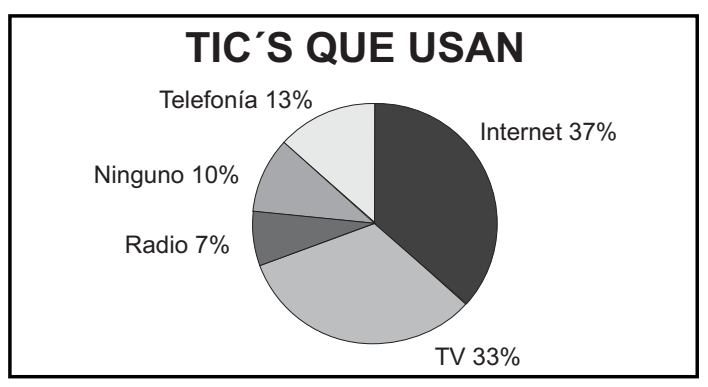

En la televisión y el internet entran en más de un $30 \%$ lo que muestra que cada uno de estos medios son los más utilizados, también concuerda con datos estadísticos que se pueden ver en el Censo de población 2012 donde se muestran que estos dos son los gigantes de la transmisión de información y las principales herramientas tecnológicas.

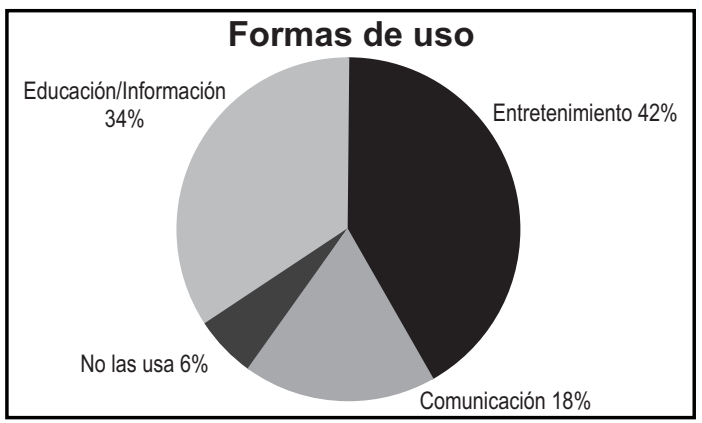

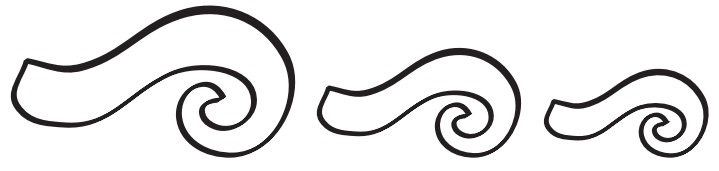

Las formas de uso son igualmente alarmantes debido a que los resultados arrojan que las tecnologías de la información se utilizan indebidamente: el $42 \%$ de los encuestados utiliza los medios para entretenimiento ocioso, dejando en segundo lugar la información y educación con un $34 \%$ de 50 encuestados.

\section{Resultados}

En Ayahualulco se conocen las tecnologías básicas, la televisión como gigante de los medios de comunicación y la principal herramienta de información que la mayoría de las personas tiene, la radio como segundo medio tecnológico de información. El internet actualmente ha invadido todos los sectores del planeta y gracias a él se obtiene información de todo tipo y la telefonía móvil que con nuevas aplicaciones fusiona tres tecnologías, el internet, la televisión y la comunicación a distancia. Estas cuatro son las más utilizadas en todo el mundo y han llegado hasta las comunidades, como ejemplo tenemos a Ayahualulco, Veracruz. De los 50 instrumentos aplicados se encontró que al menos el $90 \%$ conoce y utiliza las tecnologías para educarse, informarse y entretenerse, el otro $10 \%$ jamás han tenido contacto con alguna de ellas. En las dimensiones de las teorías de la comunicación educativa realizadas por Zulma Aramayo (1996) se establece que la teórica-tecnológica es utilizar de manera eficiente las tecnologías de la información para un correcto de desarrollo individual educativo y personal, en el caso de Ayahualulco se cumple con este factor del estudio de Zulma Aramayo (1996).

El uso de las tecnologías de la información se realiza con distintos propósitos, dependiendo del enfoque con el que se analice, publicidad es relacionado con el entretenimiento e innovación, educación se relaciona con los gadjets y herramientas que nos ofrecen las tecnologías, uso personal que depende de la cultura que se tenga de las tecnologías a utilizar. En Ayahualulco se descubrió que la mayoría de 


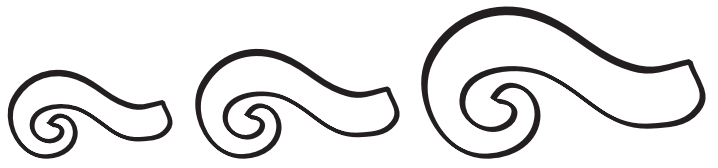

los usuarios de las tecnologías de la información las usan para entretenerse, aparece una variable donde 28 encuestados además de utilizar las tecnologías por ocio también las ocupan para educarse, informarse y comunicarse por lo que un mínimo de tiempo es ocupado por esta segunda variable y la primera la mayor parte del tiempo disponible, del promedio de 1 hora con 10 minutos, 50 minutos son dedicados al entretenimientos y 20 minutos para las tres subcategorías mencionadas. La Dra. Ana María Fernández (1997) establece en su estudio que con la actividad comunicativa no sólo se transmiten contenidos, también se transforman convicciones, sentimientos y desarrollo de las capacidades del individuo, en Ayahualulco al hacer uso de las tecnologías se cambian estos factores que establece el estudio, aunque su uso sea en su mayoría de entretenimiento, sí hay un cambio donde el mensaje se transmite ya de otras formas.

Educación y su relación con las TIC'S antes y después, la educación es muy escasa y la mayoría de los habitantes solo termina su educación básica sin aspiraciones de continuar con los niveles superiores, las tecnologías llevan poco de haber entrado a esta comunidad y no influyen tanto, la mejora se nota pero no en gran medida, de los 50 encuestados el 87\% (44 personas todas jóvenes) admitieron que su educación ha sido y fue tradicional, que las tecnologías llegaron tarde y que a veces las ocupan para hacer tareas, el otro 13\% (6 personas que no estudiaron) las tecnologías no influyeron en nada, esos 6 encuestados fueron padres de familia y adultos mayores que mencionaron que es importante para sus hijos porque les permite un mejor desarrollo académico. En el estudio de la comunicación educativa de la Dra. Ana María Fernández (1997) se establece que los procesos sociales condicionan la evolución educativa de una persona, el contenido educacional y el contexto forman parte importante y que la educación se desarrolla efectivamente cuando estos factores son favorables, en el uso de las TIC'S les sirve a los

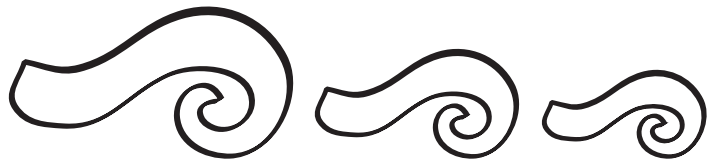

estudiantes de las comunidades para realizar trabajos y tareas, lo que permite un mejor desarrollo educativo, para el alumno y para el docente.

Respecto a la importancia que los habitantes de Ayahualulco le dan al uso y manejo de las TIC'S en sus vidas, las personas encuestadas compartieron su posición ante las tecnologías de la información que están llegando poco a poco a sus comunidades y lo que significan en sus vidas, el 75\% (35 personas) de los 50 encuestados aseguraron que es muy importante el uso y saber manejar las tecnologías que les podrán dar nuevas herramientas de crecimiento y un mejor futuro, el 22\% (11 personas) mostró que es de muy poca importancia el uso y manejo de las tecnologías de información, para ellos es más importante trabajar y mantener a la familia por lo que los estudios también quedan de lado, finalizando el 8\% (4 personas) mencionaron que no importan las tecnologías y que jamás las ocuparían porque no estaban en condiciones para utilizarlas y no sabrían como sacarles beneficio. En el estudio de comunicación educativa ya mencionado en los puntos anteriores también se refiere a que la interacción y uso son importantes para el proceso educativo y formativo. Comparando el estudio de la Dra. Ana María Fernández (1997) las personas hacen un proceso simple donde priorizan lo que les pueden traer beneficios para sus vidas, en el estudio la relación de las formas educativas modernas es siempre importante para un crecimiento, la mayoría de los encuestados piensa que son importantes, pero mientras no sean de uso cotidiano y sencillo simplemente no se presentarán como una prioridad.

Infraestructura escolar y privada, las escuelas y las casas que se visitaron durante el proceso de recolección de datos mostraron que de las 10 observaciones ambas subcategorías se encuentran en condiciones de pobreza extre$\mathrm{ma}$, las condiciones son rurales y las tecnologías que se observaron fueron televisores, 


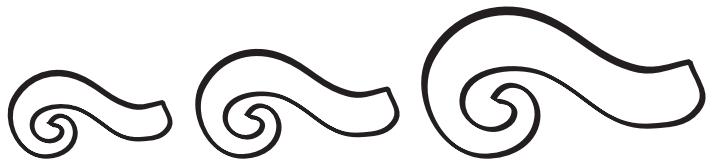

radios, teléfonos celulares, en cuestión de internet no se observó ninguna computadora por lo que se demuestra que las tecnologías siguen sin tener un impacto grande en la educación de los habitantes de Ayahualulco, Veracruz. En cuestión contextual no se menciona nada en los estudios donde se compara la investigación realizada, en tal caso se resuelve que es indispensable contar con buen material tecnológico para el aprendizaje y su uso debe ser adecuado para el crecimiento de las personas, en Ayahualulco no pudimos observar este desarrollo infraestructural debido a la economía y falta de servicios.

\section{Conclusión}

En esta investigación el objetivo era conocer la realidad de Ayahualulco en cuanto al conocimiento y manejo de las TIC'S, así como el uso que se les da a las mismas. De igual forma se pretendía constatar con qué Medios de Comunicación cuentan y cómo influyen en su diario vivir y desarrollo como comunidad rural, para posteriormente poder diseñar y ofrecer alternativas para un aprovechamiento más crítico y constructivo de los Medios para una vida y educación dignas.

Tras aplicar los instrumentos adecuados para obtener dicha información, pudimos darnos cuenta que la mayoría de la población desconoce el uso y manejo de las nuevas tecnologías, el $60 \%$ (27 personas, 25 adultas y 2 jóvenes) entran en este caso de neoanalfabetas. Los fines de uso son entretenimiento y las tecnologías que manejan en un $90 \%$ son televisión y radio de los 50 entrevistados, un 100\% en las observaciones aplicadas.

En realidad el uso educativo de las tecnologías no se lleva a cabo, debido a que: 1 . No se cuentan con los recursos o herramientas necesarias, 2 . No existe señal de internet o cobertura para la telefonía celular, 3 . No existe personal capacitado para enseñar a la comunidad a utilizar el manejo de las TIC'S.

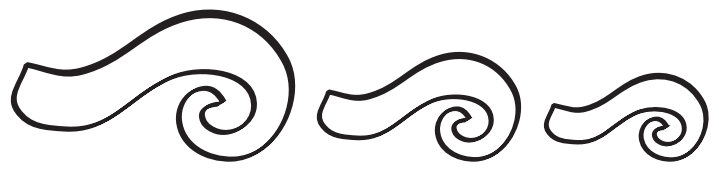

¿Se toman en cuenta su entorno cultural y su circunstancia geográfica para impartirles una educación escolar adecuada?, es la primer pregunta y con base en los datos y resultados obtenidos durante el proceso, se llega a la conclusión de que para los habitantes no es importante el entorno cultural, en cuestión de geografía existe una adaptación por lo que la educación queda como un elemento básico y sin trascendencia en la vida de los habitantes.

¿Qué tanto o de qué forma inciden los Medios de Comunicación Social en la vida y desarrollo de las comunidades de Ayahualulco?, los mediossimplemente les ofrecen un panorama general, donde las perspectivas en su mayoría son violentas y de desorden público, el impacto es grande ya que ha impedido el uso y adquisición de las tecnologías de información. En cuanto a su desarrollo es fútil debido a que la mayor parte del tiempo la dedican a tareas del hogar, trabajos físicos como el campo o laboral y educación en una mínima parte.

La formación escolar que reciben, ¿̇les permite un desarrollo humano y económico digno?, es una conclusión que los datos arrojan como una alerta para este tipo de comunidades, en cuanto a desarrollo humano les permite un mejor convivio y organización, para lo económico es totalmente inservible ya que los habitantes y en especial los jóvenes tienen el concepto de que la educación es algo que se debe hacer por un compromiso y una vez terminado este no es necesario explotar todo el potencial que les ofrecería.

¿Qué elementos culturales influyen más en su modus vivendi?, las celebraciones y la religión católica son aspectos culturales demasiado arraigados para ellos, forman parte de su desarrollo como individuos y como sociedad, les permite una mejor convivencia y desarrollo sustentable, debido a las relaciones que comparten. 


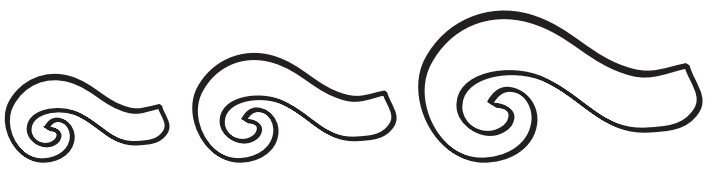

¿Qué recursos propios de su entorno se pueden aprovechar para desarrollar un proyecto educativo sustentable?, los recursos ambientales y de reciclaje parecen ser los que podrían aprovechar para su desarrollo educativo y de proyectos, lo necesario con base a los resultados serían programas donde se les brindara la oportunidad de desarrollarlos y un sistema que le diga cómo llevarlos a cabo.

La principal limitante de esta investigación fue el tiempo, no se pudo visitar la totalidad de viviendas debido a que los investigadores solo estuvieron una semana en aquella comunidad, pero se pudo constatar que no existen escuelas suficientes y que las establecidas cuentan con pocos alumnos de altos niveles educativos. No existen preparatorias, únicamente la de La Salle Ayualulco y no está disponible para todos los habitantes del municipio, ninguna escuela o vivienda contó con tecnologías especializadas de comunicación e información como computadoras y telefonía, en su mayoría contaba con radio y televisores. En cuestión de relaciones investigador- sujeto se encontró una barrera de confianza poco estable por lo que no se pudo aplicar de forma correcta el instrumento de observación por lo que la investigación se limitó al 100\% de los instrumentos de entrevista y un $25 \%$ de observación.

Lo que la investigación nos permite recomendar con base en los resultados, a lo observado y al contexto previamente estudiado es:

1. Implementar un programa general de culturalización de tecnologías de información a cada comunidad, sería un proceso donde se dieran pláticas comunales y se introdujera a la gente el sentido de estas tecnologías.

2. Maestros voluntarios completamente capacitados para que la educación en las comunidades se disparará al menos en un $200 \%$, esto con el fin del creci-

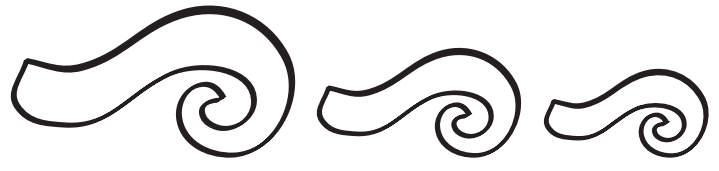

miento y fortalecimiento del habitante joven, los maestros actuales deberían tomar más cursos y capacitaciones de docencia si quisieran seguir dando clases.

3. Que se impulsen los programas educativos para que se continúen los estudios superiores, esto con el fin de que lo jóvenes tengan mayores oportunidades de crecimiento y puedan tener un buen desarrollo sustentable.

4. Las tecnologías a las que tengan acceso darles un uso correcto y así poder avanzar en cuestiones más avanzadas, en relación los adultos y gente mayor para que tengan un panorama más amplio y correcto de la realidad, para los jóvenes radicaría en el ámbito educativo donde se afrontan a tecnologías más complejas.

5. Antes de intentar que las tecnologías impacten y entren en contacto con los habitantes de Ayahualulco, sería importante que las herramientas educativas fueran actualizadas y se desarrollaran tareas que obligaran por distintos medios a que se relacionaran con las tecnologías, esto en un nivel básico debido a su poca interacción.

6. Sería adecuado que alumnos con facultades y rendimiento mayor fueran capaces de transmitir sus conocimientos a las zonas que no tienen oportunidad de bajar o llegar a una escuela con los recursos necesarios para su correcto aprendizaje y desarrollo educativo.

7. Tener un programa móvil donde se actualice a la gente, se le informe al menos tres veces a la semana de que pasa en zonas urbanas y que se mencionen las ventajas y propuestas que las tecnologías de información ofrecen a personas que viven en sus condiciones. 
8. La elaboración de medios informativos para los habitantes, no de manera masiva por el factor económico que implica, pero sí la implementación de pizarras o pancartas que expongan los hechos e información de utilidad para los habitantes.

9. Los docentes deben tener un conocimiento avanzado de las tecnologías de información para que los alumnos cuenten con todas las herramientas para su crecimiento y que puedan elaborar de manera individual y autosuficiente programas para la mejora educativa y económica.

10. Al terminar los estudios de secundaria incentivar a los alumnos a que estudien la prepa, el sacrificar algunos años de trabajo para que puedan aportar mayor ingresos a sus hogares y planificación correcta de la familia en el caso de la pronta sexualidad que muestran los jóvenes desde secundaria.
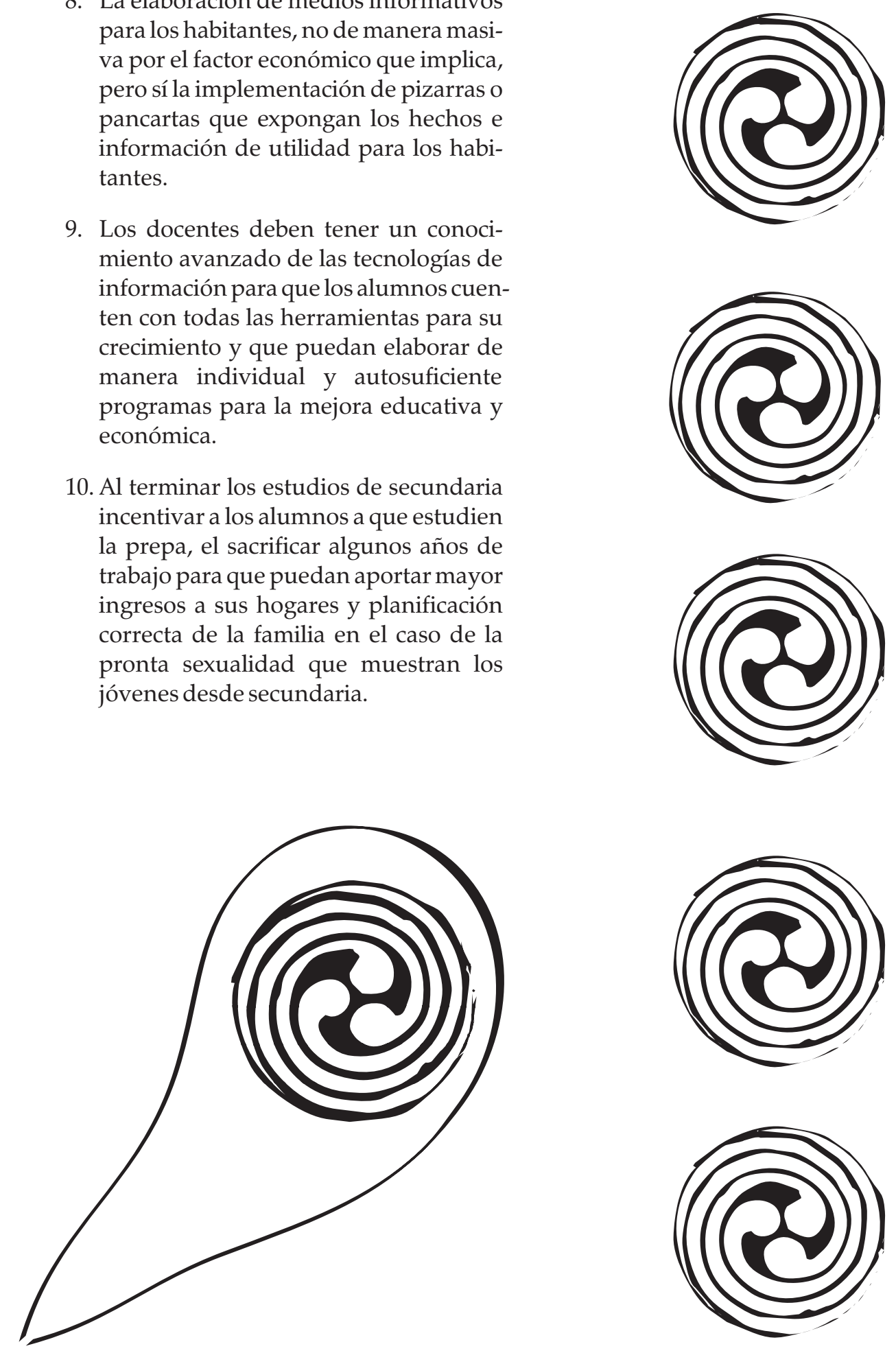


\section{Fuentes de consulta:}

Propuesta y Validación de un Modelo de Calidad en Educación Infantil, Tesis Doctoral, Covadonga Ruiz de Miguel, Madrid, 2002:

Conde Obregón, Ramón. (1995) Confucio: vida y enseñanzas. Barcelona, Verón. Editor.

Microsoft Encarta (2006) Educación del Siglo XX. Microsoft Corporation.

Yanes Guizmán Jaime (2011) Las TIC'S en la educación. http://mercadonegro. wordpress.com/2007/08/05/la-educacion-actual-incluida-la-mediada-por-tecnologias-de-lainformacion-y-las-comunicaciones-no-puede-darse-alejada-del-contexto-socioculturalde-los-aprendicez-donde-estos-se-transforman-en-los/. Consultado el 24 de marzo de 2012.

Sartori, Giovanni (2008) Homo videns. La sociedad teledirigida. México. Prentice Hall.

Gómez Mont Carmen (2003) Nuevas Tecnologías de comunicación. México Editorial Trillas.

Reynoso Castellanos, Angelina T. (2000) Introducción a las tecnologías de la información. México. Editorial Pearson Educación.

Indermit, Guasch, Maloney, Perry, Shady (2005) Cerrar la brecha en educación y tecnología. Colombia, Bogotá. Ed. Banco Mundial.

DES/INTAL (1984) Progreso económico y social en América Latina. Estado Unidos de América. Ed. Banco Interamericano de Desarrollo.

Miñón Romero, Lucía G. (2005) La pobreza en las familias de "Caminando Unidos". México. Ed. Universidad La Salle Cuernavaca.

Schettino, Macario (2009) México. Problemas sociales, políticos y económicos. México. Editorial Pearson.

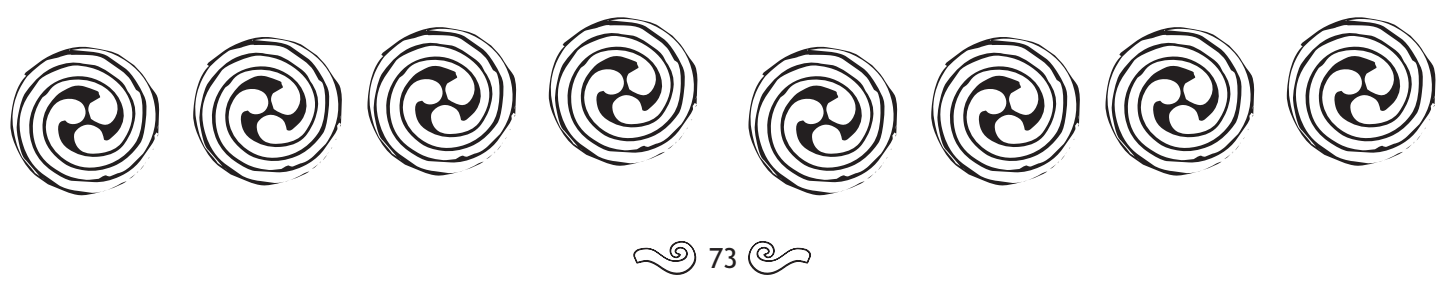




$$
\beta
$$

